\title{
Dr. J. D. Hanawalt
}

The powder diffraction community was deeply saddened to hear of the recent death of J. D. (Don) Hanawalt at his home in Ann Arbor, Michigan. Don collapsed and died early in the morning of June 26,1987 . His death came as a shock to many of us since Don, despite heart problems in recent years, seemed to be almost immortal. His continuing active participation in the powder field belied his advancing years and even now, it is hard to accept that he was 84 years old when he died.

Don Hanawalt studied at Oberlin College and the University of Wisconsin. He was also a National Research Fellow of the Rockefeller Foundation, studying X-ray Absorption Spectra at the University of Michigan and the University of Gronigen in The Netherlands. After the second world war, Don spent a summer in Germany as a member of the U.S. Department of Commerce Technical Investigation Team. In 1957 he was a member of the metallurgical exchange delegation to the U.S.S.R. Don was professor emeritus of the University of Michigan and he retained a desk there until his death.

To the whole of the X-ray powder community, Don Hanawalt is known as the father of the pattern storage and retrieval system still in use today. Indeed, Hanawalt's work in this area while still with the Dow Chemical Company, along with Ludo Frevel and the late Sid Rinn, formed the basis of a qualitative multi-phase analysis method which has stood the test of time for more than 50 years. But this project was only one side of Hanawalt's technical career. To many metallurgists, Hanawalt was one of the world's authorities on magnesium chemistry. In 1943 he received the Mathewson Gold Medal Award from the Institute of Metals, for his work on the corrosion of magnesium and its alloys. He also received the gold medal of the American Society of Metals as well as honors from the Magnesium Association and the American Society for Testing and Materials.

When, in 1969, the Joint Committee of ASTM Committee E4 on Powder Diffraction Standards became an in- dependent corporation, Hanawalt was one of five original incorporators (along with Bill Fink, Roger Simard, Morris Brooke and the late LeRoy Wyman). Don served on the original Board of Directors of the International Centre (then JCPDS) from 1970 to 1979 , and was Chairman of the Board from 1976 to 1978 . But apart from assisting in the corporate direction of the International Centre for Diffraction Data, Hanawalt's biggest contribution lay in his Technical Committee work. At one time or another, he served on almost every subcommittee and subgroup of the International Centre, but was most active on his beloved subcommittee on Search/Match methods. While maintaining a staunch attachment to the well tried and proven manual methods, he was more than willing to accept the role of the computer in this area. I myself recall many heated discussions in the early 1970 's as to the relative merits of old and new. But in all this, he remained a humble man, always ready to listen to others and to give advice when it was requested.

In addition to his scientific work, Don was active in many civic organizations including the Boy Scouts, the Willard and Martha Dow Memorial Education Fund, the Memorial Presbyterian Church, plus numerous organizations in Midland including the Figure Skating Club, the Little Theatre Guild, the Music Foundation and the Rotary Club. He was an avid (and reasonably proficient) tennis player and still played regularly until recent years. For those fortunate enough to have visited his home, he was a charming host, with a wealth of anecdotes.

Don's first wife Leonore died in 1978. He is survived by their three children, eight grandchildren and by his second wife, Dorothy. He leaves behind a host of friends - he will be sorely missed.
Ron Jenkins Managing Editor Powder Diffraction 